\title{
Transição demográfica e transição do consumo urbano de água no Brasil ${ }^{\star}$
}

\author{
Roberto Luiz do Carmo* \\ Ricardo de Sampaio Dagnino *** \\ Igor Cavallini Johansen ${ }^{\star \star * *}$
}

\begin{abstract}
Este artigo discute que, embora o volume da população seja um aspecto relevante a se considerar na relação entre população e ambiente, existem outros fatores que podem ser ainda mais importantes. Na perspectiva demográfica, elementos como a composição e distribuição espacial da população são fundamentais. Em termos ambientais, o estilo de desenvolvimento e o nível de consumo são decisivos. O Brasil vive um momento de transições flagrantes. Por um lado, existe a transição demográfica (queda nas taxas de mortalidade e natalidade), marcada pelo rápido declínio na taxa de fecundidade total, de cerca de 6 filhos por mulher, em 1960, para menos de 2 filhos, em 2010. Por outro lado, há uma transição de consumo, discutida neste trabalho tendo como referência a melhoria da situação econômica do país e o aumento do consumo de água, que é causado tanto pela expansão do sistema de abastecimento em áreas urbanas quanto pela tendência de aumento do gasto per capita. Assim, enquanto houve uma redução significativa das taxas de crescimento populacional, o consumo de água apresentou tendência de aumento, como resultado de alterações nos padrões de acesso e níveis de consumo.
\end{abstract}

Palavras-chave: Transição demográfica. Água. Consumo. População. Ambiente.

\footnotetext{
* Os autores agradecem aos pareceristas e ao Comitê Editorial da Rebep pelas valorosas contribuições para o aprimoramento deste trabalho. Também agradecem aos técnicos do Ministério das Cidades, que esclareceram as dúvidas que surgiram no processo de trabalho com os dados do Sistema Nacional de Informações sobre Saneamento (SNIS). E aos financiamentos parciais do CNPq (Processo 311965/2013-0) e Projeto Urbis-Amazônia.

${ }^{\star *}$ Instituto de Filosofia e Ciências Humanas, Universidade Estadual de Campinas - Unicamp, Campinas-SP, Brasil (roberto@ nepo.unicamp.br).

${ }^{\star \star \star}$ Instituto de Filosofia e Ciências Humanas, Universidade Estadual de Campinas - Unicamp, Campinas-SP, Brasil (ricardosdag@gmail.com).

**** Instituto de Filosofia e Ciências Humanas, Universidade Estadual de Campinas - Unicamp, Campinas-SP, Brasil (igorcavallini@gmail.com).
} 


\section{Introdução}

A relação entre população e ambiente tem sido marcada historicamente pela abordagem que salienta a relação entre volume populacional e disponibilidade de recursos ambientais. Essa discussão teve seu início com Malthus, em 1798, ao destacar que o crescimento populacional não poderia ser sustentado pela capacidade de produção de alimentos (SZMRECSÁNYI, 1982). O argumento malthusiano, todavia, tem sido sistematicamente negado pela realidade, seja por meio do desenvolvimento tecnológico, que expandiu a capacidade produtiva e diversificou a base de produção, seja pelas mudanças e adaptações sociais, com a criação de instrumentos de regulação dos usos dos recursos ambientais. À medida que os problemas ambientais recrudescem, ressurgem os ecos malthusianos, trazendo o controle do crescimento populacional como principal proposta para solução das problemáticas ambientais (LAM, 2011).

O recente aumento da preocupação com as questões relativas às mudanças climáticas novamente reacende a discussão sobre a necessidade de se controlar o crescimento populacional enquanto mais elementar - e muitas vezes única - ação necessária para enfrentar as decorrências do "novo" conjunto de perigos ambientais em nível global. Todavia, há autores que questionam esta análise simplista acerca da relação entre as dinâmicas populacional e ambiental, como é o caso de Stern (1997), Kates (2000), Sawyer (2002) e Dalton et al. (2008). Suas abordagens serão discutidas neste artigo, na seção que trata das relações dinâmicas entre população, ambiente e consumo de água.

Não se pretende negar aqui que a questão do volume populacional seja importante, pois um número maior de pessoas exige mais investimentos em termos de infraestrutura e serviços básicos, que são necessários inclusive para diminuir a vulnerabilidade social diante das mudanças climáticas. Entretanto, existem outros aspectos a serem considerados na relação entre população e ambiente, como o consumo da população. Dois dos mais importantes aspectos do consumo são o padrão (como se consome) e o nível (quanto se consome). Assim, uma população reduzida, mas com um nível de consumo elevado, pode gerar problemas ambientais significativos.

Dessa forma, o objetivo do presente texto é apresentar as tendências recentes de transição do consumo da água no Brasil, com o aumento da utilização desse recurso proporcionado tanto pela expansão do sistema de abastecimento em áreas urbanas quanto pela tendência de crescimento do consumo per capita. Procura-se demonstrar que o nível de consumo, condicionado pela capacidade econômica, pode ser o fator decisivo no aumento da demanda sobre recursos.

Para tanto, considera-se especificamente o consumo de água encanada nas economias residenciais urbanas. Justifica-se essa opção metodológica pela elevada concentração populacional no meio urbano, com quase $85 \%$ da população brasileira residindo nestas áreas, segundo dados do Censo 2010 do Instituto Brasileiro de Geografia e Estatística (IBGE), e também pelo fato de o estilo de vida urbano, por meio do processo de "urbanização 
extensiva" descrito por Monte-Mór (2005), ser decisivo em termos de configuração do padrão do consumo de recursos ambientais. Soma-se a esses aspectos centrais a disponibilidade de dados em uma série histórica sistematizada sobre o consumo de água em áreas urbanas. Este trabalho está inserido em uma agenda iniciada em Carmo (2001) e retomada em Carmo et al. (2007, 2011, 2013).

Nesse contexto, em que se torna cada vez mais necessário entender a relação entre dinâmica demográfica e seus desdobramentos para a demanda e uso da água, revelamse questões bastante complexas, especialmente em termos teóricos e metodológicos. A abordagem utilizada neste texto foi construída no âmbito dos estudos da relação entre população e ambiente, desenvolvida principalmente no campo dos estudos demográficos.

A análise da relação entre população e ambiente envolve duas esferas da realidade que, embora estejam estreitamente interligadas, geralmente são abordadas de maneira estanque, como chamam a atenção Lutz et al. (2002). Outro grande problema metodológico nos estudos de população e ambiente, identificado por Hogan (2001, p. 457), refere-se à unidade de análise, pois raramente os dados populacionais são comparáveis a dados ambientais, em termos da unidade geográfica empregada. Assim, os dados sobre a dinâmica demográfica estão relacionados a escalas espaciais e temporais circunscritas pela administração pública, obedecendo a limites político-administrativos, como municípios, estados, países. Já os processos ambientais não obedecem a esses limites, sendo caracterizados por dinâmicas que interagem em escalas espaciais e temporais específicas.

Um dos maiores desafios é encontrar bases de dados que sejam capazes de fornecer informações compativeis entre as escalas dos processos. As informações demográficas, por exemplo, são obtidas, principalmente, por meio dos Censos Demográficos do IBGE, que reúnem os dados mais confiáveis para todos os municípios do país, com periodicidade decenal. As informações ambientais, por seu turno, são setoriais, dependendo do elemento "natural” a ser considerado (água, ar, solo, entre outros). Como a proposta aqui é trabalhar com a questão do consumo de água, optou-se por utilizar uma base de dados ainda pouco consultada (GAMA, 2009), que é o Sistema Nacional de Informações sobre Saneamento (SNIS), do Ministério das Cidades. As informações sobre consumo de água do SNIS são apresentadas por divisão política (estadual e municipal), o que permite relacioná-las com os dados de população do IBGE disponibilizados a partir da mesma escala espacial de análise.

Salienta-se que o consumo industrial e o agropecuário não serão abordados diretamente, embora representem de longe o maior volume demandado e consumido, considerando o total do país. Cerca de 20\% do consumo de água no Brasil é destinado à atividade industrial, enquanto $62 \%$ são direcionados à produção agrícola. O uso doméstico, por sua vez, representa apenas 18\% do consumo total de água no país, segundo dados de 1998-2002 provenientes do AquaStat e citados por Carmo et al. (2007). Existe uma demanda crescente de água destinada à produção de commodities, especialmente soja e carne, conforme discutido por Carmo et al. (2007). Embora o consumo seja relativamente menor em termos de volume, é no ambiente urbano que são tomadas as decisões que afetam diretamente o 
consumo de água. Ou seja, na atualidade, são as demandas provenientes das áreas urbanas que estabelecem as diretrizes gerais para as atividades produtivas agropecuárias e industriais, constituídas por padrões de produção e de consumo específicos. Nesse sentido, entender como a água é consumida no ambiente urbano pode ajudar a compreender o contexto mais geral do consumo de água.

Destaca-se, ainda, que existem situações bastante diferenciadas no conjunto do país em termos de consumo, sendo que em algumas bacias hidrográficas grande parte da água é destinada ao consumo urbano, como é o caso da bacia do Alto Tietê, onde se localiza a Região Metropolitana de São Paulo (CARMO, 2002). É preciso citar, também, a presença de uma grande quantidade de aspectos relacionados com os recursos hídricos urbanos, como drenagem urbana e contaminação de mananciais (TUCCI, 2006), que, embora influenciem a disponibilidade de água para consumo, não serão abordados nesse trabalho.

Considerando o consumo de água nas áreas urbanas, a tendência tem sido de crescimento da demanda em termos de volume. Esse aumento ocorre pela conjunção de dois fatores: ampliação do número de domicílios a serem atendidos, o que é extremamente relevante em termos de extensão do serviço de abastecimento para toda a população, garantindo melhores condições de vida e de saúde; e aumento do consumo per capita, que está relacionado principalmente com a maior capacidade econômica das famílias. É este ponto que o presente texto focaliza.

As mudanças na dinâmica demográfica podem trazer novas situações e possibilidades em termos da configuração da demanda por água no Brasil. Vislumbram-se, para as próximas décadas, a continuidade da diminuição significativa do crescimento populacional e até mesmo o início do declínio em termos de volume em meados do século XXI (IBGE, 2013). Nessa perspectiva, é fundamental pensar, principalmente considerando-se as mudanças que deverão ocorrer em termos da estrutura etária da população nas próximas décadas, quais são os elementos que certamente afetarão a demanda por água e as possibilidades em termos de políticas públicas eficazes para a gestão da água.

\section{Transições no Brasil ao longo do século XX}

O Brasil passou por mudanças importantes ao longo do século XX. A queda da mortalidade seguida pela redução da natalidade da população brasileira compreendeu o processo denominado transição demográfica, que resultou em e foi resultado de alterações significativas em termos sociais, políticos e econômicos no país. Do mesmo modo, houve transformações não menos importantes na redistribuição espacial da população, com a concentração populacional nos centros urbanos, correspondendo à chamada transição urbana, processo que se deflagrou durante a segunda metade do século passado. Tais mudanças ou transições precisam ser mais bem compreendidas com vistas a elucidar a dinâmica dos processos demográficos em curso atualmente no país. À análise dessas transições - a demográfica e a urbana - dedicam-se os breves comentários apresentados a seguir. 


\section{Transição demográfica}

A princípio, é fundamental destacar que a dinâmica demográfica é resultado de processos históricos socialmente construídos, característicos de determinado tempo e espaço, o que explica as grandes diferenciações existentes entre países, entre regiões dentro de um mesmo país e entre grupos sociais dentro de uma mesma região.

Um aspecto básico para a compreensão das mudanças demográficas em curso é o entendimento dos componentes da dinâmica demográfica e da relação que se estabelece entre esses componentes. De maneira simplificada, pode-se dizer que a variação bruta do número de indivíduos de determinado grupo populacional, considerando-se um momento específico no tempo e um certo espaço geográfico, decorre do balanço entre os nascimentos, os óbitos e os movimentos migratórios.

No contexto histórico recente, um dos processos mais marcantes da dinâmica demográfica é a chamada transição demográfica (DYSON, 2011), que corresponde a um processo decorrente da diminuição das taxas de mortalidade e natalidade, que ao longo do tempo declinam e tendem a se equilibrar em patamares mais baixos, conforme discutem autores como Kirk (1996), Lee (2003), Lesthaeghe (2010), Galor (2011) e Reher (2011). Considerando-se uma situação em que a migração não seja significativa em termos de volume, essas mudanças na natalidade e mortalidade levam a uma transformação na estrutura etária da população, provocando o "envelhecimento demográfico", que é o aumento do peso relativo dos idosos no conjunto da população, conforme apontam Carvalho e Garcia (2003), Wong e Carvalho (2006) e Carvalho e Wong (2008).

$\mathrm{O}$ acentuado crescimento populacional brasileiro verificado no início do século XX deveu-se, principalmente, à chegada de imigrantes internacionais. De acordo com dados do Instituto Brasileiro de Geografia e Estatística (IBGE, 2006), a taxa bruta de mortalidade no Brasil era da ordem de 27,8 óbitos por mil habitantes, em 1900, chegando a 6,5 por mil na década de 2000. ${ }^{1}$ Nesse mesmo período, a taxa bruta de natalidade passou de 46 nascimentos por mil habitantes para 21,5 por mil. O declínio da mortalidade foi mais acentuado durante as décadas de 1940 e 1970, quando se verificaram as maiores taxas de crescimento populacional em decorrência do crescimento vegetativo.

Um dos principais elementos desse processo é a evolução das taxas de fecundidade total (TFT), que dizem respeito ao número de filhos por mulher em idade reprodutiva (entre 15 e 49 anos). Segundo Berquó (2001), no Brasil, a TFT era de 7,7 filhos por mulher em 1903. De acordo com os dados da Ripsa (2009), esse número declinou lentamente até atingir 5,8 em 1970, sendo que daí em diante a queda foi brusca, chegando a 2,5 em 1991 e ficando abaixo do nível de reposição (2,1 filhos por mulher) a partir de 2003. Apesar dos diferenciais existentes entre regiões, grupos de renda e faixas de idade, a TFT apresentou tendência de

\footnotetext{
${ }^{1}$ Destaca-se a importância da queda da mortalidade infantil - muito acentuada principalmente na segunda metade do século XX -, que passou de 163,6 para 45,3 óbitos por mil nascidos vivos em 1990 (IBGE, 2006), continuando em queda até atingir 15,3 por mil em 2011 (IDB, 2012).
} 
declínio generalizada ao longo das décadas mais recentes, conforme descrevem Berquó e Cavenaghi (2006).

Nesse sentido, a acentuada diminuição das taxas de crescimento populacional está diretamente relacionada à redução da fecundidade durante a segunda metade do século XX. Esse processo está associado a transformações sociais e econômicas, tais como industrialização, urbanização, mudanças no papel social da mulher e na família, disponibilidade e difusão do uso de métodos anticoncepcionais, entre outros (GOLDANI, 2001; BRYANT, 2007). Conforme salientam Potter et al. (2010), a queda da fecundidade ocorreu primeiramente e de maneira mais intensa nas regiões onde os indicadores de nível de escolaridade das mulheres eram maiores.

De acordo com Brito (2008), a transição demográfica é um processo único, por atingir toda a sociedade brasileira, mas é também múltiplo, tendo em vista que se manifesta conforme as diversidades regionais e sociais. As decorrências também serão diversas. Por exemplo, se o crescimento da população em idade ativa (15 a 59 anos), por um lado, representa um potencial considerável em termos econômicos, o chamado "bônus demográfico", por outro, caso não seja adequadamente aproveitado, pode significar uma fonte de pressão sobre o mercado de trabalho. O envelhecimento relativo da população, principalmente considerando-se as taxas significativas de crescimento da população idosa, exigirá adaptações em termos de políticas sociais, especialmente nas áreas de saúde e de previdência social.

O declínio significativo da mortalidade, entre 1940 e 1960, e a permanência da fecundidade em níveis elevados resultaram em uma população brasileira jovem e em rápido crescimento (CARVALHO; WONG, 2008, p. 598). Em 1991 evidencia-se, pela primeira vez, o impacto da queda da fecundidade, com diminuição do peso relativo do segmento de 0 a 4 anos. Essa tendência acentuou-se no tempo, com a forte redução da base da pirâmide etária. A queda da fecundidade faz com que o peso relativo das crianças (0 a 14 anos), no conjunto da população, seja cada vez menor ao longo dos anos. Por outro lado, o aumento da esperança de vida, decorrente da diminuição da mortalidade infantil e da ampliação da longevidade, também contribui para que o segmento de idosos, acima de 60 anos, ganhe participação cada vez maior no conjunto da população brasileira.

Como resultado da dinâmica demográfica apresentada, a população do Brasil cresceu de maneira significativa durante o século XX. O primeiro Censo Demográfico do país registrou, em 1872, um total de 9,9 milhões de pessoas. Em 1900, a população chegou a 17,4 milhões, alcançando 51,9 milhões em 1950 e totalizando 190,7 milhões de habitantes segundo o Censo Demográfico 2010, com um acréscimo de 21 milhões de habitantes durante a primeira década do século XXI.

Embora o aumento tenha sido expressivo em valores absolutos, devido à inércia demográfica, verificou-se diminuição das taxas geométricas anuais de crescimento da população brasileira, que atingiram seu ápice na década de 1950 (3,17\% ao ano) e, desde então, apresentaram declínio constante, registrando um aumento da população total do país 
da ordem de 1,17\% ao ano na década de 2000. Destaca-se que o incremento populacional é mais acentuado nas áreas definidas como urbanas, enquanto as áreas rurais tendem a perder população em grande parte dos municípios brasileiros. O declínio acentuado das taxas de crescimento e as mudanças na estrutura etária evidenciam que o Brasil já se encontra em uma fase adiantada da transição demográfica.

Em síntese, o processo da transição demográfica mostra que a chamada "explosão demográfica”, tão em voga nas décadas de 1960 e 1970, faz parte do passado para o Brasil, muito embora essa discussão ainda seja retomada no país de tempos em tempos, em função de situações específicas. O volume máximo de população a ser atingido pelo país ficará bem abaixo até mesmo das projeções realizadas no início dos anos 2000, que apontavam para um máximo de 246 milhões na década de 2050, começando a diminuir depois desse momento (CARVALHO, 2004).

As conclusões dos dados das Pesquisas Nacionais por Amostra de Domicílios (PNADs) da década de 2000, corroboradas pelas informações obtidas pelo Censo 2010 do IBGE, confirmaram que as taxas de fecundidade continuaram diminuindo durante os anos 2000 , indicando que a população brasileira deverá atingir um volume populacional máximo de cerca de 228,4 milhões de habitantes na década de 2040, tendendo a diminuir o volume populacional na década seguinte (IBGE, 2013). Em 2010, nas áreas definidas como urbanas, residiam 160,9 milhões de pessoas (84\% da população total). Mantida essa proporção, de acordo com as projeções do IBGE (2013), na década de 2040, haverá um volume próximo de 192 milhões de habitantes nas áreas urbanas. Caso aumente para 90\% a concentração da população urbana, serão 205 milhões os residentes nessas áreas. Isso significa que, nas próximas décadas, poderá ocorrer um aumento de 30 a 45 milhões de habitantes nas áreas urbanas, o que corresponde a um volume bastante relevante e que precisa ser considerado.

Entretanto, é necessário ir além dessa discussão sobre o volume de população e levar em conta outros elementos que estão envolvidos na dinâmica demográfica, como a redistribuição espacial da população - especialmente por meio da concentração em áreas urbanas ao longo da segunda metade do Século XX - e as mudanças no nível de consumo da população brasileira, com a ampliação do uso e acesso à água tratada nessas áreas urbanas.

\section{Transição urbana no Brasil}

Concomitantemente à transição demográfica, e em interação complexa com esta, uma característica marcante do crescimento populacional brasileiro é a sua concentração em áreas definidas como urbanas, o que pode ser chamado de transição urbana.

A transição urbana aconteceu de maneira rápida. Em 1950, cerca de 36,2\% da população (18,8 milhões de pessoas) vivia nas áreas definidas como urbanas. Já em 2010, esse percentual passou para 84,4\% do total, correspondendo a 160,9 milhões de pessoas (IBGE, 1950; 2010), ou seja, um acréscimo de 142,1 milhões de pessoas, nesse período. A velocidade do processo e o volume da população envolvida explicam, pelo menos em parte, 
os problemas de infraestrutura que persistem nas cidades brasileiras, que estão amplamente discutidos na literatura (OJIMA, 2007; SILVA; MONTE-MÓR, 2010).

Outro problema desse processo rápido de crescimento urbano foi a configuração de um déficit habitacional histórico. Nota-se que, para suprir esse déficit - apesar de entre 1970 e 2010 as taxas de crescimento, tanto da população urbana quanto do número de domicílios urbanos, terem diminuído de maneira constante e significativa -, a taxa de crescimento do número de domicílios tem sido superior às taxas de crescimento populacional, especialmente nas áreas urbanas. A taxa geométrica anual de crescimento da população urbana brasileira passou de 4,5\% ao ano, em 1970, para 1,6\%, em 2010. No mesmo período, a taxa de crescimento dos domicílios urbanos brasileiros passou de 5,6\% para 2,8\% ao ano. Ou seja, no período mais recente, a velocidade de aumento do número de domicílios urbanos ainda continua expressiva.

Essa acentuada ampliação do número de domicílios pode ser explicada também pelas mudanças recentes na estrutura dos arranjos familiares, com o aumento relativo de famílias de tamanho reduzido e de pessoas residindo sozinhas (TOMÁS, 2013), acarretando uma densidade domiciliar cada vez menor na ocupação dos domicílios. De acordo com o Censo Demográfico, entre 2000 e 2010, houve um declínio da ordem de 13,2\% no número médio de moradores por domicílio, passando de 3,8 para 3,3 pessoas, nesse período. No contexto estadual, as médias oscilaram entre 3,0, no Rio Grande do Sul e no Rio de Janeiro, e 4,3 habitantes por domicílio, no Amazonas e Amapá. MacKellar et al. (1995) já haviam destacado a importância dessa questão da composição dos domicílios tanto para as discussões relativas aos padrões de consumo, especificamente no caso de energia, quanto no que diz respeito às emissões de poluentes.

Sawyer (2002) estabelece interações entre o tamanho, a distribuição e a composição da população brasileira com os níveis e padrões de consumo, mediados pela estrutura de classes, pelo mercado e pelas políticas públicas. 0 autor aponta que o crescimento do número de domicílios pode implicar o maior consumo de bens duráveis (geladeiras, fogões, por exemplo), assim como de água e energia. Da mesma forma, o envelhecimento populacional é capaz de contribuir para o crescimento do consumo de bens duráveis, como resultado da acumulação ao longo do ciclo de vida.

A seguir discute-se como esses processos, que caracterizaram a dinâmica demográfica ao longo do século XX, afetam a dinâmica ambiental, considerando especificamente a água.

\section{População, ambiente e consumo de água}

O debate público acerca das relações entre as dinâmicas social e ambiental mantevese restrito, por vezes, a duas visões distintas e contrapostas. De um lado havia aqueles que apontavam os países pobres como causadores do "desastre ambiental”, à medida que a depleção dos recursos naturais, seguida pelas mudanças climáticas e a perda de 
biodiversidade, era resultado do rápido crescimento da população daqueles países. Assim, para preservar o ambiente para as futuras gerações, seria necessário concentrar esforços nos países mais pobres, ao passo que neles estaria ocorrendo a vasta maioria do volume de crescimento populacional (NATIONAL RESEARCH COUNCIL, 1999). De outro lado, em abordagem desenvolvida em resposta à primeira, afirmava-se que os países ricos eram os responsáveis pela degradação ambiental, argumentando que estes utilizariam mais recursos e energia. De acordo com essa perspectiva, julgava-se necessário o corte do excesso de consumo nos países ricos para preservar o ambiente e possibilitar que os mais pobres pudessem alcançar condições de vida aceitáveis (STERN et al., 1997).

De acordo com Kates (2000), ao contrário da população, cujos fenômenos (nascimentos e mortes) são relativamente bem definidos como fenômenos biológicos, não há consenso similar sobre o que a noção de consumo compreende. Para os físicos, o consumo abrange transformações de matéria em energia com crescente entropia. Os economistas afirmam que o consumo trata de gastos do consumidor com bens e serviços, diferenciando-se, por consequência, da sua produção e distribuição. Para os ecologistas, o consumo denota a obtenção de energia e nutrientes ao se alimentar de algo, em geral vegetais ou outros consumidores de vegetais. Os sociólogos, por sua vez, distinguem o consumo como um status simbólico, especificamente quando indivíduos e unidades domésticas utilizam suas rendas para implementar seu status social por meio de certos tipos de compra. Kates (2000) aponta, então, a existência de três grandes grupos de elementos definidores do consumo: energia, materiais e informação.

Existem dificuldades para se trabalhar a questão do consumo, principalmente em sua relação com a dinâmica da população. Se, de um lado, os dados populacionais são amplamente coletados e acessíveis, de outro, as informações sobre transformação de energia, materiais e informação são limitadas e não há dados agregados em unidades comuns a nível global, apenas para alguns tipos específicos de classes de materiais. Kates (2000) sugere que existe uma interessante similaridade entre a transição demográfica e uma transição no que diz respeito à utilização de energia, materiais e informação. Nessa transição, as sociedades usarão crescentes montantes de energia e materiais à medida que o consumo cresce.

Dalton et al. (2008), por sua vez, afirmam a necessidade de se verificarem os efeitos que as mudanças composicionais da população realizam sobre a demanda de energia e as emissões de gases como o dióxido de carbono $\left(\mathrm{CO}_{2}\right)$. Os autores sustentam que diferenças nos padrões específicos de renda, entre outras variáveis, implicam, direta e indiretamente, distintos níveis de consumo e demanda de energia.

O debate sobre a relação entre produção e consumo é abordado por Sawyer (2002), que distingue a tradição marxista como aquela que dá prioridade à produção como determinante último da vida social, enquanto os economistas neoclássicos afirmam que a produção responde ao mercado e às próprias decisões do consumidor, que são, supostamente, soberanas. 0 autor presume a existência de uma interação em forma de "via de mão dupla" entre produção e consumo e que este, embora amplamente determinado pela produção, não 
é dela um simples reflexo. Assim, consumidores finais, empresas e governos adquirem bens e serviços levando em conta um amplo leque de critérios econômicos, políticos e culturais, proporcionando respostas às estruturas produtivas.

Sawyer (2002) assevera ainda que, para explicar o crescimento do consumo no Brasil, é preciso salientar o papel central desempenhado pela estabilização econômica mantida a partir década de 1990. Em termos gerais, houve um crescimento do consumo dos estratos de baixa renda depois do Plano Real de 1994, em decorrência da redistribuição resultante da eliminação das altas taxas de inflação. Em seguida, observou-se o acesso ao crédito facilitado pela estabilização econômica, estimulando o consumo dos bens duráveis.

Seria possível relacionar esse cenário recente de estabilização econômica com mudanças no nível de consumo de água no Brasil? Certamente buscar estabelecer relações mecânicas e simplificadoras entre conjuntura macroeconômica e consumo de água não é condizente com a complexidade e dinâmica da realidade. Todavia, é sim possível identificar tendências que apontam, por exemplo, para mudanças no nível de consumo de água no Brasil. Essa problemática, central na discussão aqui proposta, é desenvolvida lançando-se mão da base de dados do Sistema Nacional de Informações sobre Saneamento (SNIS), disponibilizada pelo Ministério das Cidades. Sobre essa fonte de dados, são apresentadas mais informações a seguir, destacando suas principais características, especialmente suas potencialidades e limites.

\section{O Sistema Nacional de Informações sobre Saneamento}

Segundo informações da Secretaria Nacional de Saneamento Ambiental (2010), em 1996 foi criado pelo governo federal o Sistema Nacional de Informações sobre Saneamento (SNIS), por meio do Programa de Modernização do Setor Saneamento (PMSS). Na estrutura atual do governo federal, o SNIS é responsabilidade do Ministério das Cidades, especificamente da Secretaria Nacional de Saneamento Ambiental.

O SNIS apoia-se em uma base de dados coletados em pesquisa realizada junto às prefeituras municipais e às prestadoras de serviços de água e saneamento. Esta base contém informações de caráter operacional, gerencial, financeiro e de qualidade, sobre a prestação de serviços de água, esgotos e manejo de resíduos sólidos urbanos. No caso dos serviços de água e esgotos, os dados são atualizados anualmente para uma amostra de prestadores de serviços do Brasil, desde o ano-base de 1995. As informações são coletadas junto aos prestadores de serviços de água e esgotos, de forma agregada para cada prestador e de forma desagregada por município. Em se tratando de resíduos sólidos, os dados são auferidos diretamente junto às prefeituras municipais.

No que se refere aos serviços de água e esgotos, desde a concepção original do SNIS optou-se por incluir todas as companhias estaduais que, na época da criação do sistema, respondiam pelo atendimento com serviços de água a cerca de 70\% da população urbana brasileira. Em relação aos prestadores locais, por razões financeiras e estruturais, decidiu-se 
adotar no SNIS uma amostra representativa do universo, a qual foi composta, no primeiro ano, pelos 27 prestadores de serviços de maior porte do país, operados em cidades com população superior a 100 mil habitantes. A escolha dos maiores serviços justificou-se pelo seu potencial de organização e, consequentemente, pela maior possibilidade de retorno das informações solicitadas.

É relevante destacar que, desde o início, a participação dos prestadores de serviços de água e esgoto, e mais recentemente dos municípios que enviam os dados sobre resíduos sólidos, é voluntária, não havendo nenhuma obrigatoriedade que os leve a fornecer os dados ao SNIS.

Desde 1996, momento da sua implantação, o SNIS sistematicamente coleta informações atualizadas de cada ano, amplia a amostra e efetua revisões na metodologia de coleta e tratamento dos dados, no glossário de termos e na relação de indicadores, além de incluir novas informações e indicadores e aprimorar o banco de dados.

Neste trabalho emprega-se principalmente um indicador do SNIS: o consumo urbano médio per capita de água (litro/habitante/dia), que na base de dados disponibilizada tem o código In022. Esse indicador permite estabelecer parâmetro de referência que, evidentemente, deve ser utilizado com cautela, pois situações específicas decorrentes da realidade local de cada sistema, especificamente justificadas, podem recomendar adequações nos valores médios. Entretanto, fica clara a evolução na cobertura ao longo do período de consolidação do banco de dados, o que pode ser notado pela expansão das informações municipais para o In022 entre 1995, 2000 e 2008 (Figura 1).

Cabe chamar a atenção para a questão da qualidade das informações sobre população, no banco de dados do SNIS, com casos de inconsistência nas relações entre população total, urbana e atendida. As informações da população atendida - total e urbana - são fornecidas pelos próprios prestadores de serviços. Como regra do SNIS, a população total dos municípios corresponde à estimativa publicada pelo IBGE para o ano de referência da amostra. Para obter a população urbana, utiliza-se o grau de urbanização de cada município calculado nas datas censitárias de referência. Assim, para os diagnósticos realizados entre 1995 e 1999, foi utilizado o Censo 1991 e, para os anos seguintes, o Censo 2000 - pela população total estimada pelo IBGE para cada município no ano de referência. Deve-se notar que a falta de exatidão das informações populacionais pode implicar a ocorrência de erros significativos, especialmente nos períodos intercensitários.

Entretanto, conclui-se que, mesmo passível de imprecisões, a representatividade dos dados fornecidos pelo SNIS possibilita uma boa segurança nas análises de desempenho e evolução da prestação dos serviços por agrupamentos dinâmicos no nível dos estados, bacias hidrográficas, macrorregiões e país, seja no ano de referência ou na série histórica de dados. 
FIGURA1

Municípios com informações para o consumo urbano médio per capita de água 1995-2008

1995

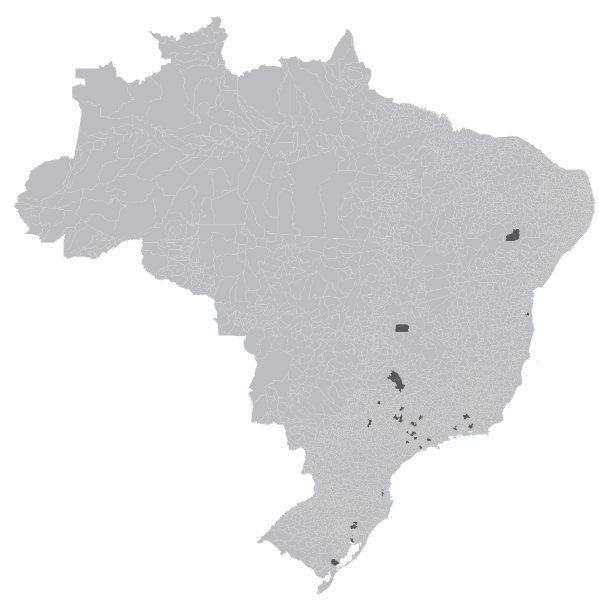

2008
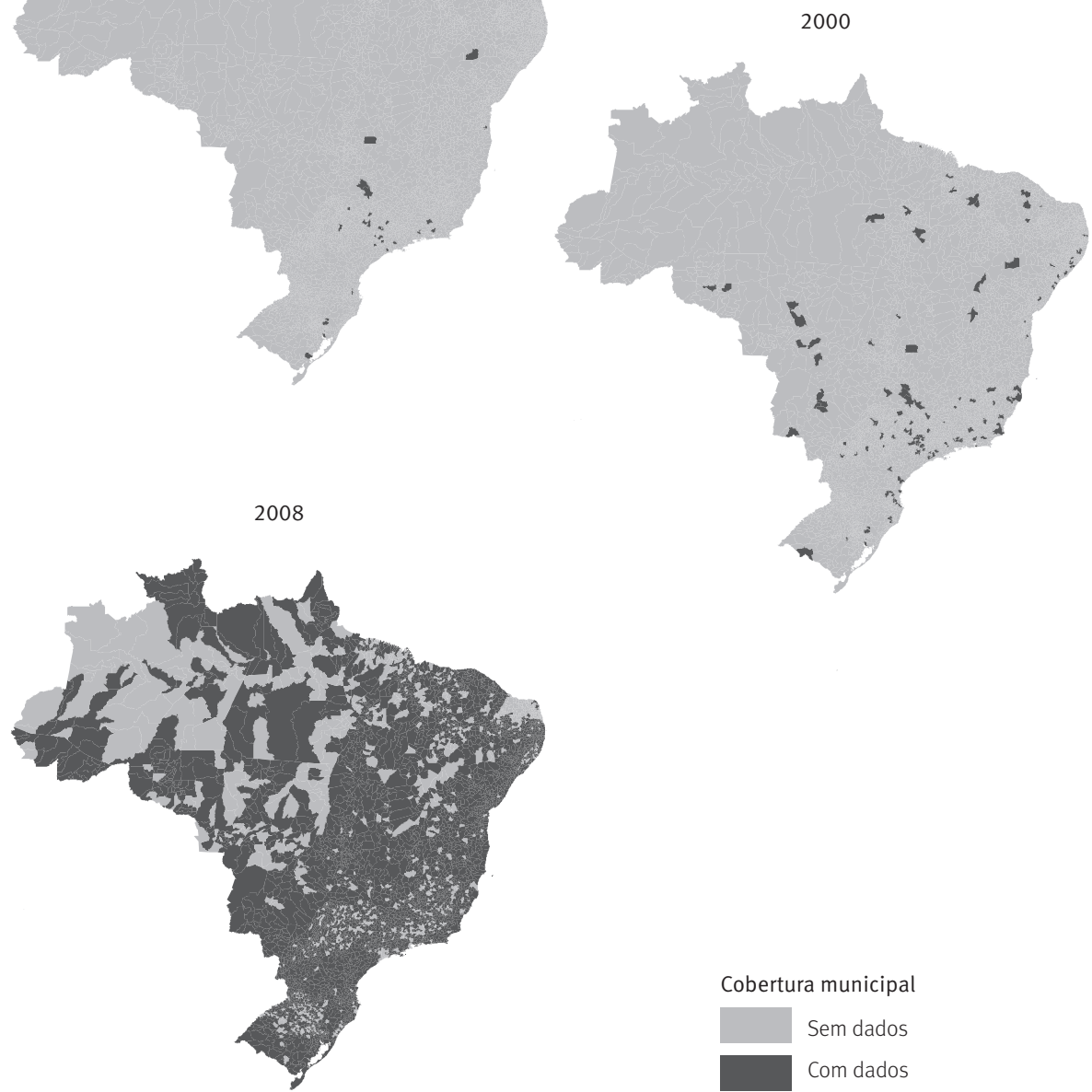

Fonte: Indicador In022 (SNIS, 2011).

\section{Transição no consumo urbano de água no Brasil}

Em termos da extensão dos serviços de saneamento básico, um dos avanços mais notáveis das décadas recentes é o aumento do número de domicílios atendidos pelo sistema de água tratada. Dados da Pesquisa Nacional de Saneamento Básico (PNSB-IBGE, 2000, 2008) indicam que o volume de água tratada distribuída por dia no Brasil passou de 44 milhões de metros cúbicos, em 2000, para 61 milhões de metros cúbicos, em 2008, o que 
corresponde a um aumento de 4,2\% ao ano. Nota-se que o crescimento foi diferenciado para as distintas regiões do país. Dessa forma, se, por um lado, a Região Sul apresentou uma ampliação do volume total de água tratada na ordem de 2,2\%, por outro, o Norte destacouse com um crescimento de 9,5\%, entre 2000 e 2008 (Tabela 1).

TABELA 1

Volume total e taxa geométrica anual de crescimento de água tratada distribuída por dia Regiões do Brasil - 2000-2008

\begin{tabular}{lccc}
\hline \multirow{2}{*}{ Regiões } & \multicolumn{2}{c}{ Volume $\left(\mathrm{em} \mathrm{mil} \mathrm{m}^{\mathbf{3}}\right)$} & $\begin{array}{c}\text { Taxa de crescimento } \\
\text { anual (\%) } \mathbf{2 0 0 0 / 2 0 0 8}\end{array}$ \\
\cline { 2 - 3 } Brasil & $\mathbf{2 0 0 0}$ & $\mathbf{2 0 0 8}$ & $\mathbf{4 , 2}$ \\
Norte & $\mathbf{4 3 . 9 9 9 , 7}$ & $\mathbf{6 1 . 0 6 3 , 5}$ & 9,5 \\
Nordeste & $2.468,2$ & $5.103,8$ & 4,7 \\
Sudeste & $7.892,9$ & $11.411,8$ & 3,9 \\
Sul & $26.214,9$ & $35.637,0$ & 2,2 \\
Centro-Oeste & $5.103,2$ & $6.055,2$ & 2,6 \\
\hline
\end{tabular}

Fonte: IBGE. Pesquisa Nacional de Saneamento Básico 2000 e 2008.

Além do acesso ao serviço de água tratada, outro tipo de consumo de água que cresceu de maneira expressiva nas décadas recentes foi o de água mineral. De acordo com o Estudo Nacional da Despesa Familiar (IBGE, 1974-1975) e a Pesquisa de Orçamentos Familiares (IBGE, 1987-2008), o consumo anual per capita de água mineral no Brasil, que era de 0,32 litro em 1974, passou para 0,60 litro em 1995 e, então, saltou para 10,95 litros em 2002 e cerca de 14 litros em 2008. Em outras palavras, houve um crescimento de mais de $4.000 \%$ no consumo de água mineral per capita no Brasil, entre 1974 e 2008.

Em termos de cobertura municipal das informações do SNIS, do total de municípios do Brasil em 2008 (5.564), nesse sistema não havia dados para 1.202 municípios (ou 22\% do total). Todavia, é preciso considerar que a informação de consumo per capita de água em 2008 permite apenas uma descrição de como se encontra a situação atual em temos de consumo de água nas áreas urbanas do país. Assim, para pensar a sustentabilidade no uso, é preciso incorporar uma dimensão histórica, que pode permitir pensar em temos de tendências de consumo. Nesse sentido de uma análise longitudinal, os relatórios do SNIS podem contribuir pouco, considerando uma escala espacial ampliada, pois a adesão ao sistema foi se consolidando ao longo do tempo, conforme pode ser observado na Figura 1.

No caso do consumo de água, os diferenciais regionais existem e são importantes, como mostra a Tabela 2, com os municípios distribuídos de acordo com faixas de consumo de água per capita. A referência adotada para a construção das faixas foi o limite de 40 litros/ pessoa/dia, estabelecido na Agenda 21 como mínimo necessário de água para o atendimento das necessidades de uma pessoa. É preciso levar em conta que há grandes diferenças de consumo entre regiões e estados no Brasil, assim como no interior dos próprios estados, microrregiões e municípios. Geralmente, o consumo elevado é mais concentrado nas capitais e no seu redor (SAWYER, 2002). 
A partir da Tabela 2 também é possível perceber que a região com maior cobertura municipal pelo SNIS, em 2008, foi o Centro-Oeste, com informações para 84\% dos seus municípios, enquanto a menor cobertura ficou com o Norte, onde $71 \%$ dos municípios apresentaram seus dados.

TABELA 2

Municípios, por faixas de consumo urbano médio per capita de água por dia Regiões do Brasil - 2008

\begin{tabular}{|c|c|c|c|c|c|c|c|c|c|c|c|c|}
\hline \multirow{2}{*}{ Regiões } & \multicolumn{2}{|c|}{$\begin{array}{l}0 \text { a } 39 \\
\text { litros }\end{array}$} & \multicolumn{2}{|c|}{$\begin{array}{c}40 \text { a } 79 \\
\text { litros }\end{array}$} & \multicolumn{2}{|c|}{$\begin{array}{c}80 \text { a } 119 \\
\text { litros }\end{array}$} & \multicolumn{2}{|c|}{$\begin{array}{c}120 \\
\text { litros e mais }\end{array}$} & \multicolumn{2}{|c|}{$\begin{array}{c}\text { Sem } \\
\text { informação }\end{array}$} & \multicolumn{2}{|c|}{ Total } \\
\hline & $\begin{array}{l}\text { N. } \\
\text { abs. }\end{array}$ & $\%$ & $\begin{array}{l}\text { N. } \\
\text { abs. }\end{array}$ & $\%$ & $\begin{array}{l}\text { N. } \\
\text { abs. }\end{array}$ & $\%$ & $\begin{array}{l}\text { N. } \\
\text { abs. }\end{array}$ & $\%$ & $\begin{array}{l}\mathrm{N} . \\
\text { abs. }\end{array}$ & $\%$ & $\begin{array}{c}\text { N. } \\
\text { abs. }\end{array}$ & $\%$ \\
\hline Total & 39 & 0,7 & 457 & 8,2 & 2.057 & 37,0 & 1.809 & 32,5 & 1.202 & 21,6 & 5.564 & 100,0 \\
\hline Centro-Oeste & 0 & 0,0 & 11 & 2,4 & 200 & 42,9 & 181 & 38,8 & 74 & 15,9 & 466 & 100,0 \\
\hline Nordeste & 25 & 1,4 & 320 & 17,8 & 757 & 42,2 & 276 & 15,4 & 415 & 23,1 & 1793 & 100,0 \\
\hline Norte & 11 & 2,4 & 64 & 14,3 & 131 & 29,2 & 112 & 24,9 & 131 & 29,2 & 449 & 100,0 \\
\hline Sudeste & 1 & 0,1 & 29 & 1,7 & 495 & 29,7 & 793 & 47,5 & 350 & 21,0 & 1668 & 100,0 \\
\hline Sul & 2 & 0,2 & 33 & 2,8 & 474 & 39,9 & 447 & 37,6 & 232 & 19,5 & 1188 & 100,0 \\
\hline
\end{tabular}

Fonte: Sistema Nacional de Informação sobre Saneamento (SNIS, 2011).

Em termos de consumo, a Tabela 2 mostra que, dos 4.362 municípios que apresentaram informação, 39 estão abaixo do consumo per capita sugerido pela Agenda 21 (40 l/hab./ dia), 457 encontram-se na faixa de 40 a 80 l/hab./dia, 2.057 na de 80 a 119 e 1.809 na de 120 l/hab./dia e mais.

Analisando as faixas de consumo e a distribuição percentual das regiões dentro de cada faixa, percebe-se que naquela abaixo do padrão da Agenda 21 (ou seja, menos de 40 l/hab./ dia) predominam municípios das Regiões Nordeste e Norte. Nas duas de maior consumo - 80 a 119 l/hab./dia e 120 l/hab./dia e mais - concentram-se os municípios do Sul e Sudeste, conforme pode ser observado no Gráfico 1 e na Figura 2.

\section{GRÁFICO 1}

Distribuição dos municípios, por faixa de consumo urbano médio per capita de água Regiões do Brasil - 2008

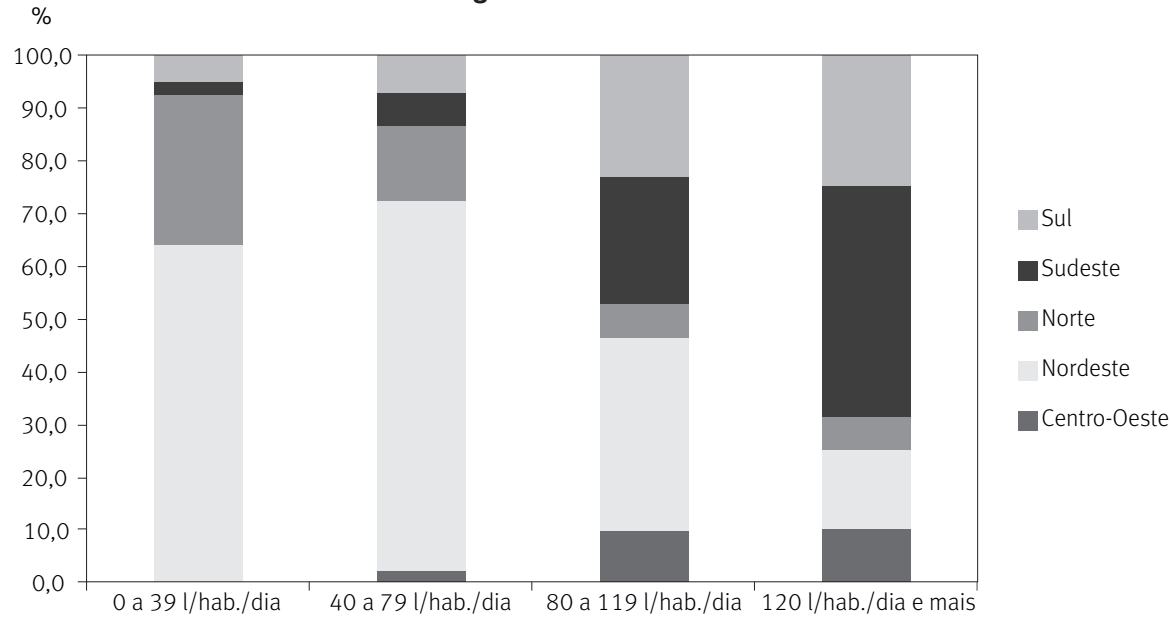

Fonte: Sistema Nacional de Informação sobre Saneamento (SNIS, 2011) 
FIGURA 2

Faixas de consumo urbano médio per capita de água Municípios - 2008

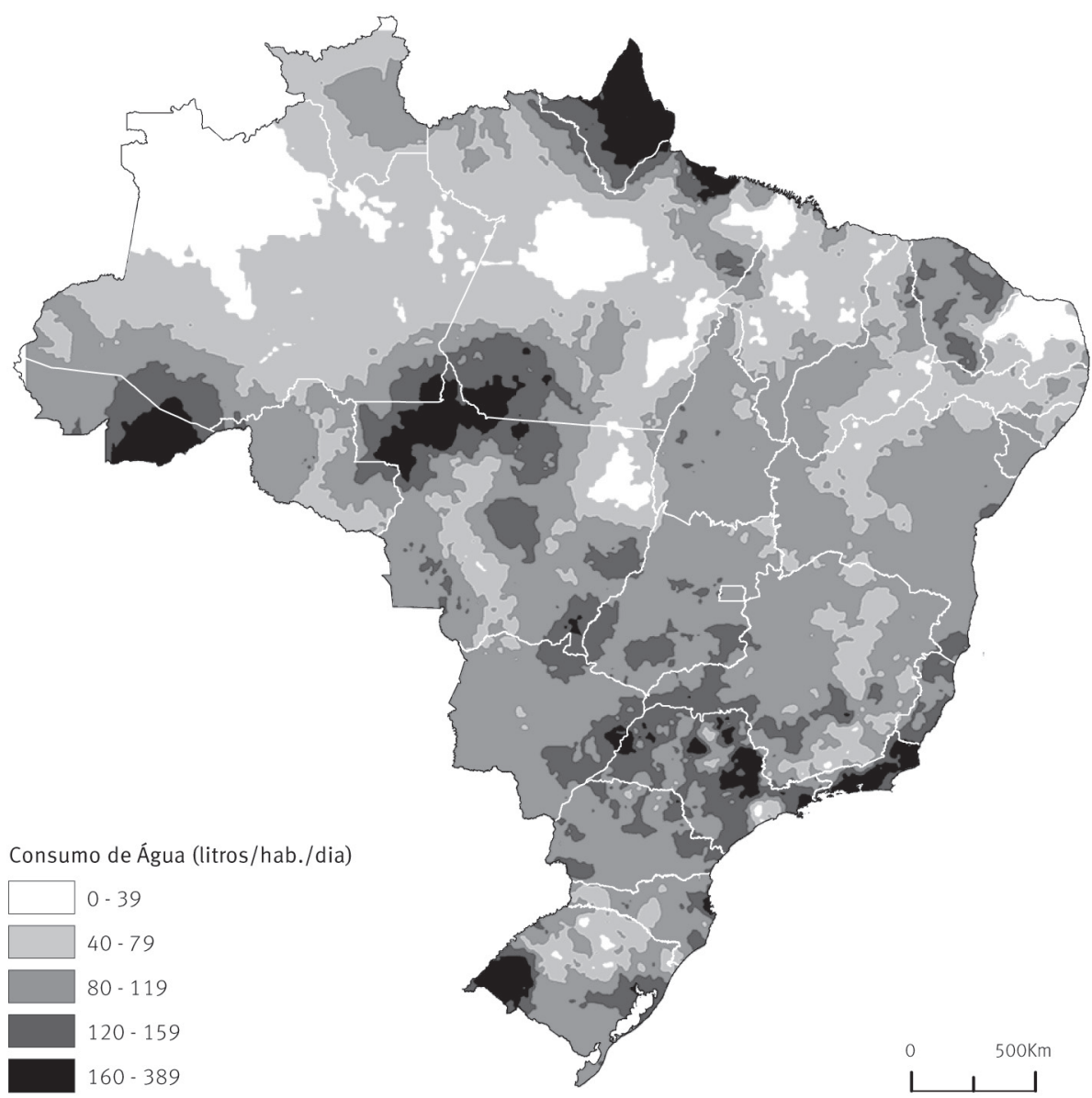

Fonte: Sistema Nacional de Informação sobre Saneamento (SNIS, 2011).

Nota: Mapa elaborado pelo método de krigagem (ordinária - exponencial) a partir dos centroides dos municípios brasileiros e dados de consumo de água no ano de 2008, baseado na variável In022 do SNIS (2011).

A Figura 2 foi elaborada pelo método de krigagem (kriging), a partir dos centroides dos municípios brasileiros com os valores de consumo de água (litros/habitante/dia) em 2008, baseado no indicador In022 do SNIS (2011). Entre as várias possibilidades metodológicas, optou-se pelo método de krigagem porque, de acordo com Isaaks e Srivastava (apud JAKOB, 2002), este método permite apresentar a informação em forma de superfície contínua de dados mais suavizados, minimizando os contrastes entre os polígonos. Assim, se, de um lado, perde-se a localização exata do evento (consumo de água na área urbana do município), de outro, ganha-se a capacidade de analisá-lo em relação aos municípios vizinhos.

Cabe notar que os valores nulos - que podem significar tanto a ausência de dado quanto o consumo realmente zero em 2008 - estão agrupados na categoria “0 a 39". Optou-se por 
fazer dessa forma visando facilitar a visualização do dado e por entender que municípios com consumo nulo são os que não prestam informação porque não dependem tanto da água coletada e distribuída no meio urbano quanto outros municípios. Finalmente, o mapa permite notar que existem "ilhas" de alto consumo de água, quer dizer, áreas que fogem do padrão geral brasileiro, principalmente no norte do Amapá, no Acre, no Mato Grosso, no extremo oeste do Rio Grande do Sul e em pequenas áreas da Região Sudeste.

As informações para todo o período histórico da base estão restritas a 14 municípios, que disponibilizaram seus dados entre 1996 e 2008 para o SNIS. São eles: Araraquara (SP), Campinas (SP), Jacareí (SP), Mogi Guaçu (SP), São Caetano do Sul (SP), São Carlos (SP), Sorocaba (SP), Juiz de Fora (MG), Poços de Caldas (MG), Uberlândia (MG), Barra Mansa (RJ), Blumenau (SC), Itabuna (BA) e Juazeiro (BA). A análise das informações sobre estes municípios, entretanto, não permite identificar tendências que sejam comuns a todos.

Com o objetivo de observar possíveis relações existentes entre nível de renda per capita e consumo de água per capita, apresenta-se, no Gráfico 2, a renda domiciliar per capita mensal das capitais estaduais, para 2000 e 2010, auferida a partir dos dados do IBGE, comparada ao consumo per capita de água para as mesmas capitais, neste caso utilizando como fonte de dados o SNIS.

Para 2000 há lacunas nas informações de consumo de água no SNIS. Assim, realizouse a média aritmética do consumo de água entre 1998 e 2002. Já o consumo de água per capita para 2010 é disponibilizado, nesse sistema, para todas as capitais, por isso o valor referente ao consumo é do próprio ano de referência.

É preciso indicar ainda que, como não há dados para o consumo de água per capita para as capitais Manaus (AM), Fortaleza (CE), Curitiba (PR) e Belo Horizonte (MG) de 1998 a 2002, período a partir do qual se realizou a média aritmética do consumo de água, essas capitais foram retiradas da análise para 2000.

GRÁFICO 2

Renda domiciliar per capita mensal por consumo urbano médio per capita de água Capitais brasileiras - 2000-2010
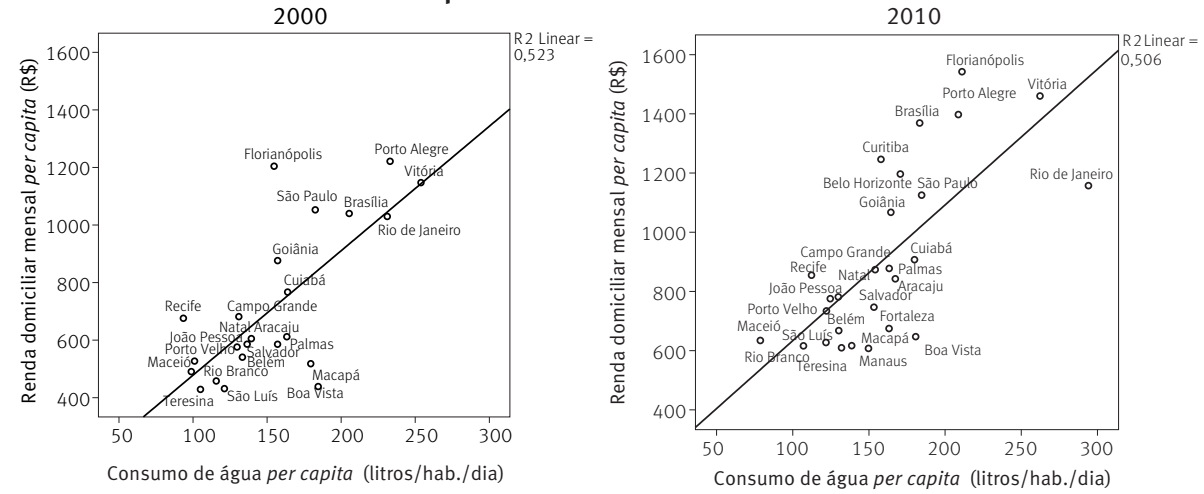

Fonte: IBGE. Censo Demográfico 2000 e 2010. Sistema Nacional de Informações sobre Saneamento (SNIS, 2011).

Nota: Utilizou-se o deflator mensal calculado pelo Índice Nacional de Preços ao Consumidor (INPC) com base nos dados do Ipeadata (http://www.ipeadata.gov.br/), levando em consideração o período de julho de 2000 a julho de 2010, devido às datas de referência do Censo Demográfico. Assim, o valor da renda em 2000 foi dividido pelo deflator calculado para o período $(0,57)$. 
Conforme se verifica no Gráfico 2, a relação entre alta renda e elevado consumo de água não é homogênea para todas as capitais. Como exemplo cita-se, para 2000, Macapá, capital do Estado do Amapá, que possui um dos mais altos níveis de consumo de água per capita naquele ano (184 l/hab./dia), mas segue em paralelo às menores rendas per capita entre as capitais brasileiras para o mesmo ano. Em contrapartida, a configuração dos dados permite observar que a renda per capita segue tendência de crescimento concomitantemente ao consumo de água tanto em 2000 quanto em 2010. Como exemplo, pode-se propor a comparação entre Rio Branco (AC) e Florianópolis (SC), em 2010. Enquanto Rio Branco possuía o consumo de água per capita naquele ano equivalente a 107 l/hab./ dia, Florianópolis registrava 211 l/hab./dia. Por outro lado, ao mesmo tempo que a renda per capita mensal na capital do Estado do Acre era de R\$ 616,22 em 2010, na capital de Santa Catarina correspondia a R\$1.542,37.

Assim, tem-se na categoria "renda" uma das possíveis variáveis - mas certamente não a única, como evidencia o $\mathrm{R}^{2}$ da reta de tendência, a partir do qual cerca de $50 \%$ da variabilidade é explicada nesta relação bivariada - capazes de ajudar a compreender o crescimento do consumo de água no Brasil atualmente. Todavia, é importante considerar que este é um estudo inicial, uma primeira aproximação, sendo as informações passíveis de um tratamento mais aprofundado no futuro, principalmente tendo em vista a evolução patente na qualidade dos dados sobre consumo de água no Brasil, assim como a ampliação do número de municípios que disponibilizam tal informação para análise.

\section{Conclusões}

O Brasil passou por um processo intenso de mudança de sua dinâmica demográfica ao longo do século XX, por meio das transições demográfica e urbana. O volume populacional e a concentração da população residindo nas cidades ainda tendem a crescer nas próximas décadas, conforme apresentado ao longo deste texto. Entretanto, além da questão da pressão dos números, existe uma grande complexidade de fatores intervenientes na demanda por recursos hídricos, entre os quais se destaca a questão das características do consumo e dos diferentes aspectos que estão envolvidos no seu padrão e crescimento.

O que se procurou mostrar neste trabalho é que, mesmo com o decréscimo significativo nas taxas de crescimento populacional, o nível de consumo seguiu pressionando no sentido de aumentar a demanda por água. Por um lado, isso pode ter ocorrido devido ao aumento do poder aquisitivo de alguns grupos da população, o que implica elevação da demanda. Por outro, contou-se com a necessidade de expansão do sistema de abastecimento, com o objetivo de alcançar 100\% da população residente em áreas urbanas.

Os dados apresentados sustentam essas afirmações, mesmo tendo em vista as limitações metodológicas decorrentes das características da obtenção das informações, cuja fonte principal, o Sistema Nacional de Informação sobre Saneamento, ainda se encontra em consolidação. Um aspecto fundamental dessa discussão é que, no novo contexto inscrito 
pela transição demográfica, existe uma série de outros elementos a serem considerados quando se aborda a relação entre população e ambiente, além de simplesmente o volume populacional.

É fato que a transição demográfica modifica a estrutura etária da população, que passa a ter um peso proporcional cada vez maior dos grupos idosos. Em estudos futuros, ainda será preciso conhecer melhor os possíveis impactos dessa nova configuração social em termos de demanda por serviços, especialmente no que tange ao consumo de água. São necessárias, portanto, pesquisas para aprofundar a compreensão dessa relação, principalmente tendo em vista que a transição demográfica disseminou-se pelo mundo ocidental ao longo de todo o século XX e deixou como resultado o envelhecimento da população.

Esse é o cenário complexo com o qual as políticas públicas no Brasil terão de lidar, principalmente no médio e longo prazos. O desafio será garantir, no que diz respeito ao fornecimento de água, que a significativa ampliação da cobertura do sistema de abastecimento possa ser sustentada e ampliada, de modo a permitir que toda a população do país tenha acesso à água tratada, sem, entretanto, exaurir os mananciais existentes.

\section{Referências}

BERQUÓ, E. Demographic evolution of the Brazilian population during the twentieth century. In: HOGAN, D. (Org.). Population change in Brazil: contemporary perspectives. Campinas: Nepo/Unicamp, 2001.

BERQUÓ, E.; CAVENAGHI, S. M. Fecundidade em declínio: breve nota sobre a redução no número médio de filhos por mulher no Brasil. Novos Estudos CEBRAP, v. 74, p. 11-15, 2006.

BRITO, F. Transição demográfica e desigualdades sociais no Brasil. Revista Brasileira de Estudos de População, v. 25, n. 1, p. 5-26, jun. 2008.

BRYANT, J. Theories of fertility decline and the evidence from development indicators. Population and Development Review, v. 33, n. 1, p. 101-127, mar. 2007.

CARMO, R. L.; OJIMA, A. L. R. O.; OJIMA, R.; NASCIMENTO, T. T. Água virtual, escassez e gestão: o Brasil como grande "exportador" de água. Ambiente e Sociedade, v. X, p. 83-96, 2007.

CARMO, R. L. do. A água e o limite? Redistribuição espacial da população e recursos hídricos no Estado de São Paulo. Tese (Doutorado) - Universidade Estadual de Campinas, Instituto de Filosofia e Ciências Humanas, Campinas, 2001.

CARMO, R. L. do; DAGNINO, R. S.; JOHANSEN, I. C. Transição demográfica e transição do consumo de água no Brasil. In: XIV WORLD WATER CONGRESS. Anais... Porto de Galinhas, 2011.

CARMO, R. L. do; DAGNINO, R.; FEITOSA, F. F.; JOHANSEN, I. C.; CRAICE, C. População e consumo urbano de água no Brasil: interfaces e desafios. In: SIMPÓSIO BRASILEIRO DE RECURSOS HÍDRICOS. Anais... Bento Gonçalves, 2013.

CARVALHO, J. A. M. Crescimento populacional e estrutura demográfica no Brasil. Belo Horizonte: UFMG/Cedeplar, 2004 (Texto para discussão, 227).

CARVALHO, J. A. M.; GARCIA, R. A. O envelhecimento da população brasileira: um enfoque demográfico. Cadernos de Saúde Pública, v. 19, n. 3, p. 725-733, 2003.

CARVALHO, J. A. M.; WONG, L. L. R. A transição da estrutura etária da população brasileira na primeira metade do século XXI. Cadernos de Saúde Pública, v. 24, p. 597-605, 2008. 
DALTON, M.; O'NEILL, B. C.; PRSKAWETZ, A.; JIANG, L.; PITKIN, J. Population aging and future carbon emissions in the United States. Energy Economics, v. 30, p. 642-675, 2008.

DYSON, T. The role of the demographic transition in the process of urbanization. Population and Development Review, v. 37 (Supplement), p. 34-54, 2011.

GALOR, O. The demographic transition: causes and consequences. Cliometrica, v. 5, 2011.

GAMA, R. G. Usos da água, gestão de recursos hídricos e complexidades históricas no Brasil: estudo sobre a Bacia Hidrográfica do Rio Paraíba do Sul. Dissertação (Mestrado) - Escola Nacional de Ciências Estatísticas, Rio de Janeiro. 2009.

GOLDANI, A. M. Rethinking Brazilian fertility decline. In: XXIV GENERAL POPULATION CONFERENCE IUSSP. Anais da Sessão de Demografia Brasileira na IUSSP. Salvador, 2001. Disponível em: 〈http://www. abep.org.br/index.htm>. Acesso em: 20 set. 2011.

HOGAN, D. J. Indicadores sócio-demográficos de sustentabilidade. In: HOGAN, D.; BAENINGER, R.; CUNHA, J.; CARMO, R. (Orgs.). Migração e ambiente nas aglomerações urbanas. Campinas: Nepo/ Unicamp, 2001.

IBGE - Instituto Brasileiro de Geografia e Estatística. Censos Demográficos 1950, 1970, 1980, 1991, 2000 e 2010.

Estatísticas do século XX. DVD, 2006.

Estudo Nacional da Despesa Familiar (1974-1975) e Pesquisa de Orçamentos Familiares (1987-2008). 2002. Disponível em: <http://www.ibge.gov.br/home/estatistica/populacao/ condicaodevida/pof/2002/comentario.pdf). Acesso em: 14 jun. 2011.

Pesquisa Nacional por Amostra de Domicílios 2001-2009. Disponível em: «http://www. sidra.ibge.gov.br/pnad/default.asp>. Acesso em: 23 jan. 2011.

.PNSB - Pesquisa Nacional de Saneamento Básico 2000 e 2008. Disponível em: <http:// www.sidra.ibge.gov.br/bda/pesquisas/pnsb/default.asp>. Acesso em: 13 jun. 2011.

Contagem da população de 1996 e 2007. Disponível em: «http://www.sidra.ibge.gov. br/>. Acesso em: 17 abr. 2011. de Janeiro, 2013.

Projeção da população do Brasil por sexo e idade para o período 2000/2060. Rio

JAKOB, A. A krigagem como método de análise de dados demográficos. In: XIII ENCONTRO DA ASSOCIAÇÃO BRASILEIRA DE ESTUDOS POPULACIONAIS. Anais... Ouro Preto, 2002.

ISAAKS, E. H.; SRIVASTAVA, R. M. Applied geostatistics. New York: Oxford University Press, 1989.

KATES, R. Population and consumption: what we know, what we need to know. Environment, v. 42, n. 3, p. 10-19, 2000.

KIRK, D. Demographic transition theory. Population Studies, v. 50, n. 3, p. 361-387, Nov. 1996.

LAM, D. How the world survived the population bomb: lessons from 50 years of extraordinary demographic history. Demography, v. 48, n. 4, p. 1231-1262, 2011.

LEE, R. The demographic transition: three centuries of fundamental change. Journal of Economic Perspectives, v. 17, n. 4, p. 167-190, 2003.

LESTHAEGHE, R. The unfolding story of the second demographic transition. Population and Development Review, v. 36, n. 2, p. 211-251, Jun. 2010.

LUTZ, W.; PRSKAWETZ, A.; SANDERSON, W. C. Introduction. Population and Development Review, v. 28, Supplement: Population and environment - methods of analysis, p. 1-21, 2002. 
MACKELLAR, F. L.; LUTZ, W.; PRINZ, C.; GOUJON, A. Population, households, and CO2 emissions. Population and Development Review, v. 21, n. 4, 1995.

MONTE-MOR, R. L. What is the urban in the contemporary world? Cadernos de Saúde Pública, v. 21, n. 3, p. 942-948, 2005.

NATIONAL RESEARCH COUNCIL. Board on sustainable development. Our common journey: a transition toward sustainability. Washington, D.C.: National Academy Press, 1999.

OJIMA, R. Análise comparativa da dispersão urbana nas aglomerações urbanas brasileiras: elementos teóricos e metodológicos para o planejamento urbano e ambiental. Tese (Doutorado) Instituto de Filosofia e Ciências Humanas, Universidade Estadual de Campinas - Unicamp, 2007.

POTTER, J. E.; SCHMERTMANN, C. P.; ASSUNÇÃO, R. M.; CAVENAGHI, S. M. Mapping the timing, pace, and scale of the fertility transition in Brazil. Population and Development Review, v. 36, n. 2, p. 283-307, Jun. 2010.

REHER, D. S. Economic and social implications of the demographic transition. Population and Development Review, v. 37 (Supplement), p. 11-33, 2011.

RIPSA - Rede Interagencial de Informações para a Saúde. Indicadores e dados básicos - Brasil 2009 (IDB-2009). Disponível em: 〈http://goo.gl/74iSY6〉. Acesso em: 10 mar. 2014.

SAWYER, D. Population and sustainable consumption in Brazil. In: HOGAN, D. J.; BERQUÓ, E.; COSTA, H. S. M. (Eds.). Population and environment in Brazil: Rio+10. Campinas: Comissão Nacional de População e Desenvolvimento/Associação Brasileira de Estudos Populacionais/Núcleo de Estudos de População, Universidade Estadual de Campinas, 2002.

SECRETARIA NACIONAL DE SANEAMENTO AMBIENTAL. Sistema Nacional de Informações sobre Saneamento: diagnóstico dos serviços de água e esgotos 2008. Brasília: Ministério das Cidades, 2010.

SILVA, H.; MONTE-MOR, R. Transições demográficas, transição urbana, urbanização extensiva: um ensaio sobre diálogos possíveis. In: XVII ENCONTRO NACIONAL DE ESTUDOS POPULACIONAIS. Anais... Caxambu, 2010.

SNIS - Sistema Nacional de Informações sobre Saneamento. Aplicativo série histórica 9. Brasília: Ministério das Cidades, Secretaria Nacional de Saneamento Ambiental, 2011. Disponível em: «http:// www.snis.gov.br>.

SZMRECSÁNYI, T. (Org.). Thomas Robert Malthus: economia. São Paulo: Ed. Ática, 1982.

STERN, P.; DIETZ, T.; RUTTAN, V.; SOCOLOW, R. H.; SWEENEY, J. L. (Eds.). Environmentally significant consumption: research direction. Washington, D.C.: National Academy Press, 1997.

TOMÁS, M. C. Reviewing family studies: a brief comment on selected topics. Revista Brasileira de Estudos de População, v. 30, n. 1, junho 2013.

TUCCI, C. E. M. Água no meio urbano. In. REBOUÇAS, A. da C.; BRAGA, B.; TUNDISI, J. G. (Orgs.). Águas doces no Brasil: capital ecológico, uso e conservação. 3. ed. rev. e ampl. São Paulo: Escrituras, 2006.

WONG, L. R. R.; CARVALHO, J. A. M. O rápido processo de envelhecimento populacional do Brasil: sérios desafios para as políticas públicas. Revista Brasileira de Estudos de População, v. 23, p. 5-26, 2006.

\section{Autores}

Roberto Luiz do Carmo é professor doutor do Instituto de Filosofia e Ciências Humanas, da Universidade Estadual de Campinas - Unicamp e pesquisador do Núcleo de Estudos de População - Nepo/ Unicamp. 
Ricardo de Sampaio Dagnino é doutor em Demografia pelo Instituto de Filosofia e Ciências Humanas, Universidade Estadual de Campinas - Unicamp.

Igor Cavallini Johansen é doutorando em Demografia pelo Instituto de Filosofia e Ciências Humanas, Universidade Estadual de Campinas - Unicamp.

\title{
Endereço de correspondência
}

\author{
Roberto Luiz do Carmo \\ Universidade Estadual de Campinas \\ Cidade Universitária Zeferino Vaz \\ Av. Albert Einstein, 1300 \\ Campinas, SP - CEP 13083-852 - Caixa-postal 6166
}

\begin{abstract}
Demographic transition and transition of urban water consumption in Brazil

In this paper we discuss that, although the volume of the population is an important aspect to be considered in the relationship between population and environment, there are other factors that may be even more important. From a demographic perspective, for example, details such as composition and spatial distribution of the population are essential. In environmental terms, the style of development and level of consumption are crucial. Brazil is going through a time of important transitions. On the one hand, the demographic transition (decreased levels of mortality and birth rates), is characterized by the rapid decline in total fertility rate, from about 6 children per woman in the 1960 s to fewer than 2 children per woman in the late 2000s. On the other hand, there is a consumption transition also in course, discussed here in the relationship between improving the economic situation and increased water consumption, which is caused by the expansion of the supply system in urban areas and by the trend toward growing per capita consumption. Thus, while there has been a significant decrease in population growth rates, water consumption tends to increase as the result of changes in access patterns and consumption levels.
\end{abstract}

Keywords: Demographic transition. Water. Consumption. Population. Environment.

\section{Resumen}

Transición demográfica y transición del consumo urbano de agua en Brasil

Este artículo discute que, aunque el volumen de la población sea un aspecto relevante a considerar en la relación entre población y ambiente, hay otros factores que pueden ser todavía más importantes. Desde la perspectiva demográfica, elementos como la composición y distribución espacial de la población son fundamentales. En lo que concierne al medio ambiente, el estilo de desarrollo y el nivel de consumo son decisivos. Brasil vive un momento de marcadas transiciones. Por un lado, existe la transición demográfica (baja en las tasas de mortalidad y natalidad), marcada por el rápido descenso en la tasa de fecundidad total, de cerca de 6 hijos por mujer, en 1960, para menos de 2 hijos, en 2010. Por otro lado, hay una transición de consumo, que se discute en este trabajo teniendo como referencia la mejora de la situación económica del país y el aumento del consumo de agua, que es ocasionado tanto por la expansión del sistema de abastecimiento en áreas urbanas como por la tendencia de aumento del gasto per cápita. De este modo, mientras hubo una reducción significativa de las tasas 
de crecimiento poblacional, el consumo de agua presentó una tendencia de aumento, como resultado de alteraciones en los estándares de acceso y niveles de consumo.

Palabras-claves: Transición demográfica. Agua. Consumo. Población. Ambiente.

Recebido para publicação em 19/02/2013

Aceito para publicação em 04/08/2013 